\title{
Erratum to: The small conductance calcium-activated potassium channel 3 (SK3) is a molecular target for Edelfosine to reduce the invasive potential of urothelial carcinoma cells
}

\author{
Konrad Steinestel $^{1} \cdot$ Stefan Eder $^{2} \cdot$ Konstantin Ehinger $^{3} \cdot$ Juliane Schneider $^{4}$. \\ Felicitas Genze $^{5} \cdot$ Eva Winkler $^{5}$ • Eva Wardelmann ${ }^{1}$ • Andres J. Schrader ${ }^{6}$. \\ Julie Steinestel $^{6}$
}

Published online: 28 December 2015

(C) International Society of Oncology and BioMarkers (ISOBM) 2015

Erratum to: Tumor Biol.

DOI 10.1007/s13277-015-4509-5

The published online paper unfortunately contained a mistake in the article title. However, it has been addressed and is not anymore present in the published copies of the article. The corrected article title is shown above.

The online version of the original article can be found at doi:10.1007/ s13277-015-4509-5.

\section{Konrad Steinestel}

konrad@steinestel.com

1 Gerhard Domagk Institute of Pathology, University of Münster, Domagkstrasse 17, 48149 Münster, Germany

2 Bundeswehr Institute of Radiobiology, Neuherbergstr. 11, 80937 Munich, Germany

3 Department of General Physiology, University of Ulm, Albert-Einstein-Allee 11, 89081 Ulm, Germany

4 Institute of Pathology and Molecular Pathology, Bundeswehrkrankenhaus Ulm, Oberer Eselsberg 40, 89081 Ulm, Germany

5 Department of Urology, Ulm University Medical Center, Prittwitzstrasse 43, 89075 Ulm, Germany

6 Clinic of Urology, Münster University Medical Center, Albert-Schweitzer-Campus 1, Building A1,

48149 Münster, Germany 